\section{Stets auf dem neuesten Stand}

Nachrichtenportale boomen. Denn wer sich heute informieren will, der wartet nur ungern auf die Berichterstattung von morgen. Schön, dass es diesen Service auch speziell für Ärzte gibt. Unter www.springermedzin.de finden Sie alles, was Sie an Neuigkeiten aus Berufspolitik, Wirtschaft und Forschung wissen müssen - schnell und unkompliziert.

W er die Ärzte Zeitung und die Magazine von Springer Medizin kennt, schätzt die gut und zuverlässig recherchierten Nachrichten. Doch der Wert einer Fachinformation ergibt sich längst nicht mehr alleine aus ihrem Inhalt. Was zählt ist die Verfügbarkeit - und in dieser Beziehung ist das Internet unschlagbar.

\section{Journalistische Qualität + \\ Aktualität $=$ e.News}

Aus der Verbindung von qualitativ hochwertigem Journalismus und der Aktualität des Internets wird aus dem bekannten Nachrichtenangebot von Springer Medizin „e.News“, die schnellste und einfachste Art, sich über alle Ereignisse im Gesundheitswesen zu informieren. Das gilt für gesundheitspolitische Nachrichten genauso wie für Neuigkeiten aus der Medizin. Alles, was sich auf kleinen und großen Kongressen, in der Forschung oder in Klinik und Praxis tut, wird in den Fachredaktionen von Springer Medizin gesichtet und aufbereitet. Als Abonnent von e.Med finden Sie darüber hinaus Hintergrundberichte, Interviews mit Meinungsbildnern oder Videobeiträge von wichtigen Veranstaltungen. Und damit Sie wirklich nichts verpassen, screenen und bewerten die Redaktionen die internationale Fachliteratur und verfolgen für Sie die Diskussionen in der Publikumspresse. So entstehen täglich über zwanzig neue Nachrichten auf dem umfassendsten deutschsprachigen Medizinportal.

\section{So behalten Sie den Überblick}

Damit Sie jederzeit den Überblick behalten, können Sie die e.News nach Stichwörtern durchsuchen oder nach Fachge-

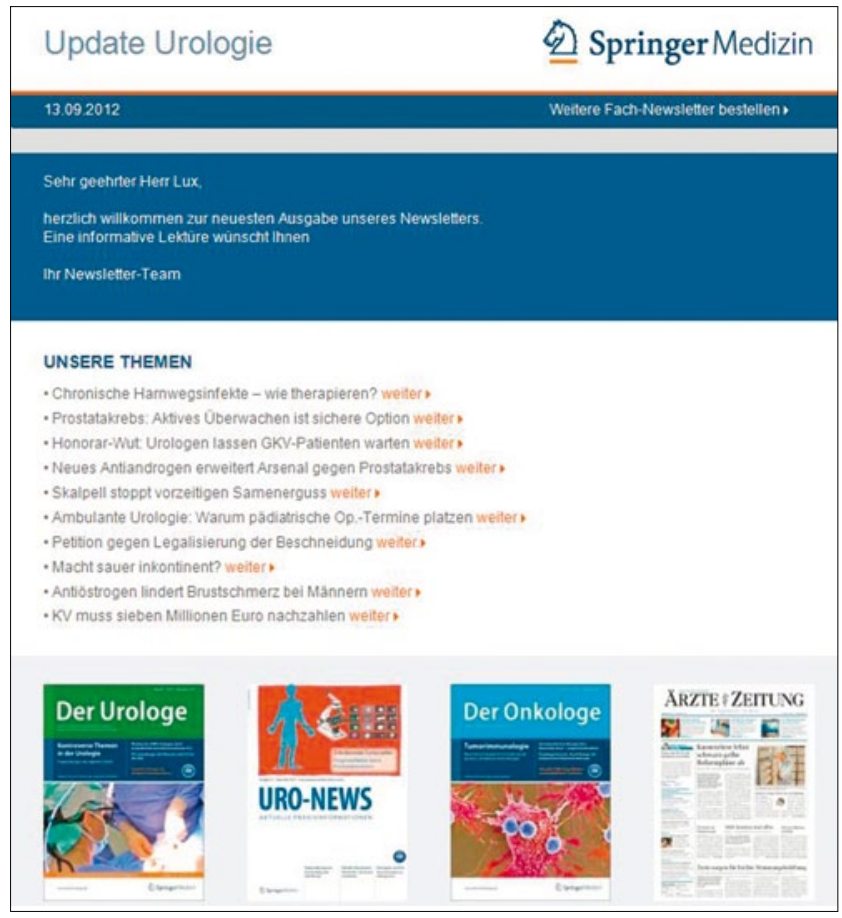

Mit den „Updates“ von Springer Medizin bleiben Sie stets auf dem Laufenden. bieten kategorisieren. In der Rubrik „Gesundheitspolitik“ beispielsweise können Sie - wenn Sie wollen - die Inhalte nach folgenden Kriterien filtern:

— Neues aus der Hauptstadt

- Aus den Regionen

_ Gesundheitspolitik international oder — Gesundheitswirtschaft

Und sollte es einmal von Belang sein, lässt sich auch die Chronologie bestimmter Entwicklungen problemlos nachverfolgen, indem Sie die „Treffer" nach deren Aktualität sortieren.

Eine komfortable Hilfestellung bei der großen Menge an Informationen bieten die „Dossiers“. Um Ihnen die Sortierung zu erleichtern, hat die Redaktion die News zu bestimmten Themen bereits zusammengefasst. Eine Liste innerhalb der Navigation zeigt an, zu welchen Themen eine solche „Sammelmappe“ vorhanden ist.

\section{Newsletter aus über 20 Fachgebieten}

Für alle, die gar nicht erst suchen wollen, bietet sich eine weitere attraktive Möglichkeit auf dem Laufenden zu bleiben. Die Newsletter von Springer Medizin liefern Ihnen alle zwei Wochen das Aktuellste aus „Politik \& Gesellschaft“, „Praxis \& Wirtschaft" und/oder den verschiedenen medizinischen Fächern direkt auf den Bildschirm. Das „Update“ aus der Allgemeinmedizin, Kardiologie, Neurologie und Onkologie erscheint sogar wöchentlich.

Bestellen können Sie die Newsletter über das Registrierungsportal von Springer Medizin (http://registrierung. springermedizin.de). Dort kann man sich auch einen Überblick über das vielfältige Newsletter-Angebot verschaffen.

Bei Fragen rund um e.Med, e.News und die „updates“ wenden Sie sich am besten an unseren Kundenservice: Tel. 0800 7780777 oder kundenservice@springer medizin.de. 